\title{
Living standards and health problems of lesser fortunate slum dwellers: Evidence from an Indian city
}

\author{
Haroon Sajjad \\ Department of Geography, Faculty of Natural Sciences, Jamia Millia Islamia, New Delhi110025, India \\ Email address: \\ haroon.geog@gmail.com
}

To cite this article:

Haroon Sajjad. Living Standards and Health Problems of Lesser Fortunate Slum Dwellers: Evidence from an Indian City. International Journal of Environmental Protection and Policy. Vol. 2, No. 2, 2014, pp. 54-63. doi: 10.11648/j.ijepp.20140202.13

\begin{abstract}
For a fast growing economy like India where most of its cities experiencing consistently increase in urban population, the future welfare of city residents is heavily relied on providing better living conditions and health prospects to the urban dwellers particularly to those who are living in miserable and unhygienic environment. The paper derived slum condition index (Slum CI) of notified and non-notified slums for assessing relative status of living conditions and health status of slum dwellers in a fast growing city. Slum CI as a composite index of its four components of household environmental index (HECI), social condition index (SCI), economic condition index (ECI) and health condition index (HCI) worked as an effective tool for identifying not only the slums requiring attention but also priorities required for the development of healthy and smart city. Slum CI based analysis revealed wide inequalities in its four components. Non-notified slums were found to have poor slum conditions. Social, economic and health conditions demand higher priority over household environmental conditions in Nangla Battu. In Shobhapur and Phelera household environmental conditions should be accorded higher priority over social, economic and health conditions. The study has also identified priorities for the notified slums which have better slum conditions. For instance, in Jamna Nagar, social, economic and health conditions and in Uttam Nagar household environmental conditions should be given higher priority for sustainable urban environmental management. Social conditions, health conditions and household environmental conditions are the outcome factors of poor economic conditions in the sampled slums. Priority based policy responses were suggested. Thus, slum condition index based approach can be utilized for assessing welfare programmes and relative status in slums, and providing holistic framework for healthy city.
\end{abstract}

Keywords: Living Conditions, Health, Slum Dwellers, Slum Condition Index, Socio-Economic Conditions, Household Environmental Conditions, Meerut City

\section{Introduction}

Slum existence worldwide and especially in developing countries is the manifestation of urbanization and consequent unplanned urban development (Bolay 2006). Rapid urbanization and human population growth especially in the developing countries like India are crucial issues. Most of the urban centres in India have witnessed the enormous growth particularly in terms of population. Level of urbanization here has increased from 27.8 per cent in 2001 to 31.1 per cent in 2011(Census of India 2001; 2011). As per the United Nations projections, if urbanization continues at the present rate, then 46 per cent of the total population will be residing in urban regions of India by 2030. This exponential growth will increase pressure on existing social and political set up and huge amount of investment will be required for providing extra infrastructural facilities for new urban settlers (Sajjad et al. 2005; Redman \& Nancy 2005). The increase in the percentage of population residing in urban areas is due to three important factors. The first factor is the rural-urban differential in the rates of natural increase. During 2001-2011, the percentage growth of population in rural and urban areas was to the order of 12 and 32 per cent respectively. The second factor is migration from rural to urban areas. The people are on constant move from backward areas to potential areas for better employment opportunities and better amenities and facilities (Rasool et al. 2012; Dyson 2011; Parkins 2010). The third reason is the reclassification of villages and towns. The number of towns have increased from 4,378 in 2001 to 7,935 in 2011 while the number of metropolitan cities having million plus population has increased from 35 in 2001 to 53 in 2011 (Census of India 
2001; 2011). Uncontrolled urbanization in India led to various types of environmental problems like shortage of housing, unprecedented water crisis, contamination of water excessive air and noise pollution, traffic bottlenecks and problem of solid waste management. The situation is worse in large and metropolises like Delhi, Mumbai, Kolkata, Chennai, Bangalore, Kanpur, Hyderabad, Meerut and many large cities presenting a depressing picture.

The heavy influx of migration from rural areas to urban places has contributed to urban growth which is in turn resulted in the development of squatter settlements and slums especially in metros and in large cities. Slums may be defined as a "compact settlement with a collection of poorly built tenements, mostly of temporary nature, crowded together usually with inadequate sanitation and drinking water facilities in unhygienic conditions" (NSSO 2003). There are two kinds of slums: notified and non-notified. Areas notified as slums by the respective municipalities, corporations, local bodies or development authorities are treated as notified slums. A slum is considered as a non-notified slum if it has a compact area of at least 300 people or about 60-70 households of poorly built congested tenements, in unhygienic environment usually with inadequate infrastructure and lacking in proper sanitary and drinking water facilities (Chandrasekhar 2006) These slums are inhabited by mainly temporary migrants, such as construction workers or other temporary workers, or new rural migrants who find it extremely difficult to get any formal housing within their paying capacity. The legal definition of slums in India, however, differs from state to state. Growth of slums in Indian cities seems phenomenonal. According to Ministry of Housing and Urban Poverty and Alleviation (2011), there were 93 million persons living in slums. There has been 45 per cent increase in the number of people living in the urban slums. The growth rate of the slum population in most cities has been much higher than the growth rate of the non-slum population. For example, from 1991 to 2001, the population of India grew at an average rate of 2 percent per annum, the urban population grew at 3 percent, mega cities grew at 4 percent, and slum populations increased by 5 percent. Thus, slums remain the fastest growing segment of the urban population, with almost double the overall growth of the urban population. It is here that the real urban crisis is being felt (Sharma 2006).

There is no particular pattern in which Indian cities both big and small are expanding. The numbers of planned urban centres are few. The majority are illustrations of how cities should not develop. Although on paper all cities have some kind of development plan, but the actual development does not follow a particular pattern except those which are directed by expediency, patronage and privileges. As a result, every city in India is the epitomic of urban chaos lacking in adequate water and sanitation, affordable housing, all weather roads, decent public transport and clean air. Cities generate wealth but increasingly Indian cities have become home to the urban poor. Every city is marked by the informal settlements where the poor are forced to live without access to basic services like water and sanitation. City administrations are unable to check the flow of poor people into the city and have failed to build affordable housing where the poor can live. Thus, the slum has now become an inescapable, vulnerable and blighted part of the Indian urban landscape. The slum dwellers are at constant risk of health hazards due to inadequate services particularly water supply, sanitation, clogged drainage, health care facilities; unhealthy site location; living and working in unhygienic environmental conditions and are bearing the brunt of increasing urban environmental problems (Karn et al. 2003; Parkinson 2007).

The concept of healthy cities project evolved by World Health Organization (WHO) as a strategy to improve health status of urban poor and slum dwellers was launched worldwide. This project was introduced in India in 1999. The main aim of this project was to focus on public health, its environmental, social and economic determinants and to improve living conditions of poor communities (WHO 1995; Harpham 2001; Goli 2011). National Urban Health Mission in India focuses on framework for implementation of healthy cities by providing primary health care facilities to urban poor and slum dwellers and strengthening public health capacity of urban local bodies (NUHM 2012). NUHM has identified 640 cities and towns reporting slums across India for strategy implementation (NUHM 2012). It requires reliable data for evaluating and monitoring core issues and priorities of slums. In view of the above, this paper makes an attempt to assess the living conditions and increasing burden of health problems among urban poor residing in slums of Meerut city, India.

\section{Study Area}

Meerut city (29 $41^{\prime}$ North latitude and $77^{\circ} 43^{\prime}$ East longitude) was chosen as the study area because and it is second largest town in the National Capital Region next to Delhi and it is also one of the cities which have been covered under the U.P. Sub Region as part of National Capital Region Development. The policy of National Capital Region for U.P. Sub Region encouraged industrial development with incentives, concessions and provision of basic infrastructure. Meerut city has four large industrial areas namely Partapur, Modipuram, Sport Goods Complex and Udyog Puram. Prominent are chemical, petro-chemical, surgical goods, plastic, rubber, leather goods, sugar mills, distillery mills, roller flour mills, straw board mills, transformer industry, spinning mills and auto-tyre factory. Meerut city has around 3,500 unorganized industrial units (not registered with the Directorate of Industries under the Factory Act). These are mainly small home based manufacturing and processing units located within 5 kilometers radius of the residential areas. Among these prominent ones are weaving industries, dyeing industries, sport goods, jewelry, scissors, blade manufacturing, silver ware manufacturing, handloom cloth, leather, spinning mills and musical instruments, etc. These 
industries are concentrated in old part of the city while large industries have grown in newly developed areas. However, due to absence of any zoning regulation or a comprehensive plan for urban environment, most of the industries in the city were located haphazardly leading to unhealthy living conditions. As a result of industrialization the heavy influx of migrants entered into city thereby created increasing demand for residential areas, shopping complexes, education facilities, drinking water facilities, health facilities, etc (Sajjad et al. 2008).

Density of population is very high in the core areas of the city. The density of population is 4,781 persons $/ \mathrm{km}^{2}$. It has experienced a continuous increase in the population of the city from 0.29 million in 1961 to 1.4 million in 2011 (District Census Handbook 1961; 2011). The population growth registered an increase of 15.92 per cent during the decade 2001-11 which could be attributed to high industrial growth during the same decade (Census of India 2001; 2011). Of the total population of the city, about 30 per cent persons live in slums having deplorable and miserable conditions (Sajjad et al. 2008). There are 102 notified slums in Meerut city. Of these, 51per cent have access to piped water supply and only 7.0 per cent have partial water supply. Only 30 per cent area is covered through sewerage system. In remaining parts of the city, people are using septic tanks and soak pits. Conventional sewage disposal system is nearly absent in the industrial areas and only some units are disposing sewage through septic tanks and soak pits (Field observation during collection of samples). There are 102 notified and 85 non-notified slums in Meerut city which have been developed due to multifunction of the city, the prime being the industrial development. This list is still in the process of revision. There are several poverty clusters in the city which are not registered in the official list owing to which they are not getting the benefits of various governments' policies and facilities. Slums in the city cover an area of approximately 240 ha and have an average population density of around 575 people per hectare. Owing to the flaws in current planning process and various ongoing government policies, practiced so far. Suffering from bias against slums these pockets have mainly been the recipients of residues and left-over of the main city, which has created abject conditions of poor hygiene and wretchedness. Such treatment of slums also failed to achieve a holistic urban growth (Jawaharlal Nehru National Urban Renewal Mission, 2006).

\section{Data Base and Methodology}

For assessing the unhygienic living conditions and environmental burden of diseases of the slum dwellers, 6 slums of Meerut city were selected randomly (Figure 1). Three notified slums constituting of Jamna Nagar, Chandra Shekhar Colony and Uttam and three non-notified slums constituting of Phelera, Nangla Battu and Shobhapur of Meerut city were chosen for analysis.

Sampling was done thoroughly in the ratio of 1: 5 of the households of the selected slums. The term household here is defined as the family members living in a dwelling and sharing the same kitchen. A total of 374 households (262 households from notified slums and 112 households from non-notified slums) were selected. These slums were sampled from Northern, Central and Southern part of the city. Among the non-notified slums, 63 households from Jamna Nagar; 108 households from Chandra Shekhar Colony and 91 households from Uttam Nagar were sampled. The total population in 262 sampled households in notified slums was 1547 persons. In non-notified slums, 46 households from Phelera, 37 households from Nangla Battu and 29 households from Shobhapur were sampled. The total population in these households was 541 persons. For data collection, a questionnaire was designed by the author and taken at each household selected. The field work was conducted during 2013.

The questionnaire was organized in such a way so to get the information regarding socio-economic conditions, living environment, environmental health, environmental attitude, environmental awareness and perception. Type of houses and their physical characteristics were self assessed on predefined checklist. The secondary data were collected from the various government bulletins and offices of Meerut city like Census of India, District Census Hand Book of Meerut published by Directorate of Census Operation, Lucknow, U.P.

Slum condition index (Slum CI) methodology is a generalization of relative approach developed by United Nations Development Programme (UNDP, 1990 \& 1992). Several studies proposed different indices as policy tools based on this relative approach (Swaminathan 1991; Saleth \& Swaminathan 1993; Hatai \& Sen 2008; Singh \& Hiremath 2010; Sajjad etal.2014).

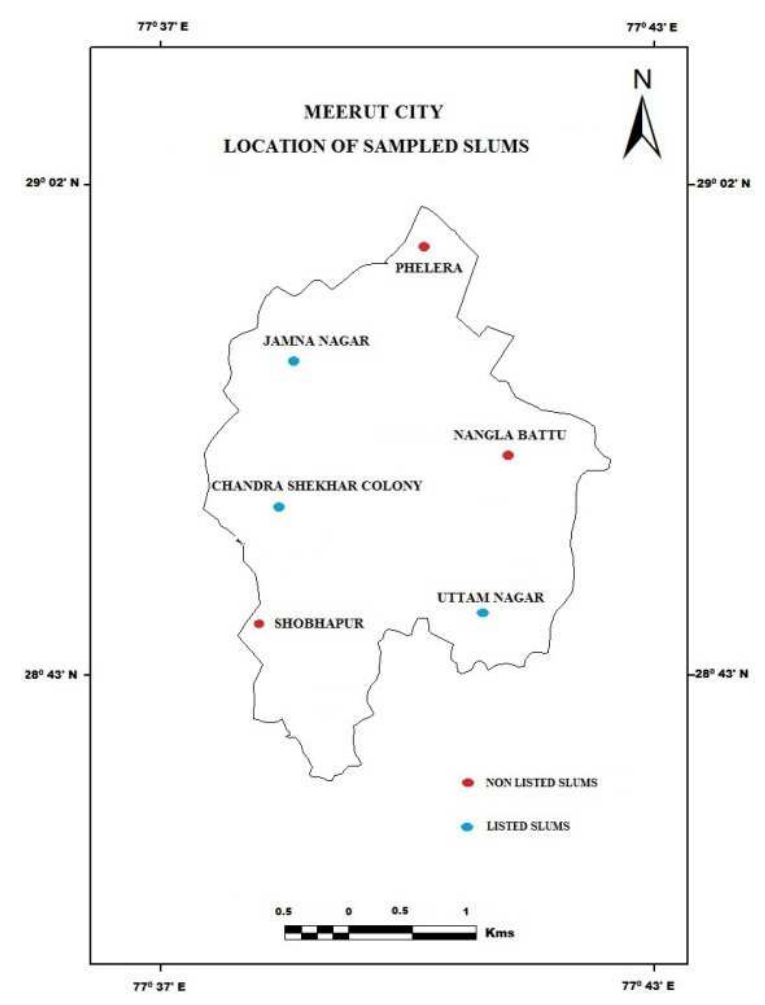

Figure 1. Location of sampled slums in Meerut city 
The analytical approach essential for operationalising slum condition index (Slum CI) is characterized by its four propositions of household environmental condition index (HECI), social condition index (SCI), economic condition index (ECI) and health condition index (HCI).

The Slum CI, the exposition of the relative approach to evaluate the relative status of a given set of entities is presented below:

Let Slum $\mathrm{CI}_{\mathrm{ij}}$ be the index for the $\mathrm{i}^{\text {th }}$ component of Slum CI related to the jth entity and let $\mathrm{X}_{\mathrm{ij}}$ be the value of the variable representing the $i^{\text {th }}$ component of Slum CI related to the $\mathrm{j}^{\text {th }}$ entity. Then the index for the $\mathrm{i}^{\text {th }}$ component of Slum CI of the $\mathrm{j}^{\text {th }}$ entity can be calculated as follows:

$$
\text { SlumCI }_{\mathrm{ijk}}=\frac{\mathrm{X}_{\mathrm{ijk}}-\min _{\mathrm{k}} \mathrm{X}_{\mathrm{ijk}}}{\max _{\mathrm{k}} \mathrm{X}_{\mathrm{ijk}}-\min _{\mathrm{k}} \mathrm{X}_{\mathrm{ijk}}}
$$

Where

$$
\begin{aligned}
& \mathrm{i}=\operatorname{Variables}(1,2,3, \ldots \ldots \ldots \ldots . \mathrm{I}) \\
& \mathrm{j}=\operatorname{Components}(1,2,3, \ldots \ldots \ldots, \mathrm{J}) \\
& \mathrm{k}=\operatorname{Slums}(1,2,3, \ldots \ldots \ldots \ldots \ldots ., \mathrm{K})
\end{aligned}
$$

For negative indicators it is expressed as:

$$
\operatorname{SlumCI} I_{\mathrm{ijk}}=\frac{\mathrm{X}_{\mathrm{max}}-\mathrm{X}}{\max _{\mathrm{k}} \mathrm{X}_{\mathrm{ijk}}-\min _{\mathrm{k}} \mathrm{X}_{\mathrm{ijk}}}
$$

The numerator in (1) measures the extent by which the $\mathrm{j}^{\text {th }}$ entity did better in the $i^{\text {th }}$ component of Slum CI as compared to the entity showing the worst performance in that component, and the denominator indicates the range (i.e. the difference between the maximum and the minimum values of the variable representing a given component), which is a simple statistical measure of total variation present in the variable representing the $i^{\text {th }}$ component of Slum CI. The denominator, in fact, serves as a scale by which the extent of the better performance of the $j^{\text {th }}$ entity in the $i^{\text {th }}$ component is evaluated. Having calculated the Slum $\mathrm{CI}_{\mathrm{ij}}$ for all the components $(i=1,2, \ldots$.,I) and all the sample entities $(j=$ $1,2, \ldots, J)$, the composite index, which measures the overall performance of a given entity (Slum CIij), can be calculated as a weighted average of all the component indices [Slum $\left.\mathrm{CI}_{\mathrm{ij}}(\mathrm{i}=1,2, \ldots, \mathrm{I})\right]$. That is:

$$
\begin{aligned}
& \operatorname{SlumCI}_{\mathrm{jk}}=\frac{\sum_{\mathrm{i}=1}^{\mathrm{I}}{ }_{\mathrm{aij}} \operatorname{SlumCI}_{\mathrm{ijk}}}{\mathrm{I}} \\
& \text { Where } \\
& \mathrm{j}=1,2,3, \ldots \ldots \ldots \ldots . . . \mathrm{J} \text { and }
\end{aligned}
$$

The $a_{i j}$ in (2) denotes the weight assigned to the $i^{\text {th }}$ component of Slum CI of the $\mathrm{j}^{\text {th }}$ entity and has the property that: $a_{1 j}+\ldots+a_{1 j}=1$. If $a_{i j}$ is identical for all $i$ and $j$ and is equal to 1 , it means that equal weights is being assumed.
Each of the four component indices of Slum CI can be based on one or more variable(s) reflecting the state of affairs in a given dimension. When there are two or more variables to represent a given component of Slum CI, the index for that component can be formed again by taking either the simple or the weighted average of the individual indices of the representative variables. The choice of the variables to represent the different components of Slum CI is influenced inter alia by their relevance and capacity to represent a given component, availability of data, and the level at which Slum CI is constructed. The following indicators were used in the estimation of four components of slum condition index:

- household environmental condition indicators: households having concrete houses, households having access to drinking water, household having sanitation facilities and households disposing off solid wastes properly;

- social condition indicators: average family size, literacy, dropouts and working children;

- $\quad$ economic condition indicators: irregular employment, mean monthly household income, three fourth share of income on food items;

- health condition indicators: access to health care, women visited hospitals for antenatal care, children immunization and infectious diseases.

\section{Results and Discussion}

\subsection{Demographic, Social and Economic Profile}

The slum dwellers in notified and non-notified slums migrated due to various pull factors. Employment opportunities, aspiration for better city life were the main pull factors which forced them to migrate. The length of stay of households in slums reveals more specifically influx pattern. Most of the households in notified slums lived for more than 16 years while most of the households in non-notified slums for 6-10 years. Thus the non-notified slums could be the newest and still expanding ones. Most of the slum dwellers in notified slums have got ration card, name in the voting list and have reportedly gained residency status. The non-notified slums comprise new settlers and do not enjoy privileges as in case of notified slums. These slums often bear the brunt of house demolition and eviction by the municipal authorities. The attainment of primary education and children attending school were surveyed in the study. The educational status of the respondents in notified slums was not very much encouraging as most of the male and female members were educated up to 5th standard. A large majority of children in notified slums are not attending school and thus are drop outs. The situation is worse in the non-notified slums as majority of males and females are illiterate and most of the children are drop outs. There is high rate of unemployment among the slum dwellers. Their aspirations of gaining economic stability after migrating to the cities were not fulfilled. The analysis 
of employment pattern of the slum dwellers shows that most of the male slum dwellers in notified and non-notified slums were engaged as daily wage earners. They worked as rickshaw pullers, Tonga pullers, industry workers and construction workers. The major businesses run by these slum dwellers are street vending, hawking, petty shop keeping and selling handicrafts. A few were engaged in services. The higher ratio of domestic women workers in both the notified and non-notified slums is attributed to the greater opportunity of women oriented work in nearby localities. Living conditions in the absence of basic services such as proper housing drinking water, sanitation and sewerage were precarious for health. They were also devoid of quality health care facilities.

\subsection{Household Environmental Conditions}

Notified slums have better household environmental conditions than non-notified slums. Among non-notified slums Shobhapur ranks lowest followed by Phelera and Nangla Battu. A large majority of the slum dwellers in Shobhapur and Nangla Battu have mud or semi-concrete houses. A structure that had either the walls or the roof but not both, made of permanent materials (i.e. brick, cement, etc) is called a semi-concrete structure (Edelman \& Mitra 2006). All these houses were over- crowded and poor both in terms of structure and ventilation, thus inviting various diseases and infections. Only 20\% households in Phelera, 9\% households in Nangla Battu and 5\% households in Shobhapur managed to live in better houses. An adequate supply of easily accessible, potable water is essential for household's welfare and a prerequisite to good hygiene and sanitation. Inadequate water supply facilities and poor sanitary conditions can have a deleterious impact on household outcomes. Field survey revealed that $15 \%$ households in Nangla Battu, 9\% households in Phelera and only 7\% households in Shobhapur had access to safe drinking water. Majority of the households in the non-notified slums use water from the government hand pumps and have to stand in long queues for the irregular and erratic public water supply. Due to this women and female children spend a considerable amount of time in fetching water. This affects the decision of the girl child to go to school and also reduces the likelihood of women participating in other economic activities. They are also not satisfied with the quality of water. The hand pumps, which are installed in their houses are generally not bored very deeply with the result that water which is pumped up is not clean; sometimes dirty, muddy water comes out. They do not have proper water storage facilities. The water is kept in open buckets or containers sometimes for days. Water storing becomes necessary during the summer months because of scarcity. During the summer and rainy seasons, diarrhea, cholera, typhoid and gastro-enteritis occur and all are caused by use of contaminated water. Majority of slums dwellers in non-notified slums did not have sanitation of any type and they use open area as well as railway track to defecate). Some households had pit (a toilet connected to a pit dug in the earth is called a 'pit latrine') while only few households used public toilets on payment basis. They were issued a card for using toilets and they have to get it renewed after the time is expired. Therefore, outdoor defecation is an outcome of long queues at public latrines. This situation poses not only inconvenience for slum dwellers but also creates a major public health hazard. Sullage consisting of effluents from toilets, bathrooms is normally discharged into soak pits. Of the total sampled households in non-notified slums, 28\% households in Nangla Battu, 23\% in Phelera and $17 \%$ in Shobhapur were disposing household solid wastes into bins (Table 1).

Table 1. Household environmental condition indicators, index and ranking of the sampled slums in Meerut city

\begin{tabular}{|c|c|c|c|c|c|c|c|c|c|c|}
\hline \multirow[t]{2}{*}{ Slums } & \multicolumn{2}{|c|}{$\begin{array}{l}\text { Households having } \\
\text { concrete houses }\end{array}$} & \multicolumn{2}{|c|}{$\begin{array}{l}\text { Households having } \\
\text { access to safe drinking } \\
\text { water }\end{array}$} & \multicolumn{2}{|c|}{$\begin{array}{l}\text { Household } \\
\text { having sanitation } \\
\text { facilities }\end{array}$} & \multicolumn{2}{|c|}{$\begin{array}{l}\text { Households disposing } \\
\text { off solid wastes } \\
\text { properly }\end{array}$} & \multicolumn{2}{|l|}{ HECI } \\
\hline & $\%$ & Index & $\%$ & Index & $\%$ & Index & $\%$ & Index & Index & Rank \\
\hline \multicolumn{11}{|l|}{ Notified slums } \\
\hline Jamna Nagar & 42 & 0.82 & 17 & 0.4 & 50 & 0.96 & 52 & 0.73 & 0.72 & 2 \\
\hline Chandra Shekhar Colony & 50 & 1.00 & 24 & 0.68 & 46 & 0.82 & 65 & 1.00 & 0.87 & 1 \\
\hline Uttam Nagar & 31 & 0.58 & 32 & 1.00 & 51 & 1.00 & 31 & 0.29 & 0.71 & 3 \\
\hline \multicolumn{11}{|l|}{ Non-notified slums } \\
\hline Phelera & 20 & 0.33 & 9 & 0.08 & 38 & 0.54 & 23 & 0.13 & 0.26 & 5 \\
\hline Nangla Battu & 9 & 0.09 & 15 & 0.32 & 41 & 0.64 & 28 & 0.23 & 0.32 & 4 \\
\hline Shobhapur & 5 & 0 & 7 & 0 & 23 & 0 & 17 & 0 & 0.00 & 6 \\
\hline
\end{tabular}

Domestic wastes constitute the bulk of all sources of solid wastes which include organic and non-organic materials, polythene bags, a variety of plastic bottles, glasses, etc. Disposal of faucal matter also constitutes the main ingredients of solid waste. The risk to health from the existence of these sites is potentially high as the waste can remain uncollected for long particularly during the rainy season, run-off and high humid conditions increase the health hazards. The land-fill sites, which are not well maintained, are prone to ground water contamination due to leachates percolation. Open dumping of garbage serves as breeding ground for diseases vector such as flies, mosquitoes, cockroaches, rats and other pests. High risk of spreading diseases like typhoid, cholera, dysentery, yellow fever, encephalitis, plague and dengue fever may not be ruled out. Among notified slums, Chandra Shekhar Colony ranks first in household environmental condition index followed by Jamna Nagar and Uttam Nagar. Though 
Chandra Shekhar Colony performed better in household environmental conditions yet it is devoid of safe drinking water and sanitation facilities. In this slum only $24 \%$ household had access to safe drinking water and $46 \%$ households had provision of improved sanitation. In Jamna Nagar access to safe drinking water index is lower than other indicators while in Uttam Nagar solid waste is not disposed at appropriate place (See Table 1).

\subsection{Social Conditions}

Social conditions were worst in non-notified slums (Table 2). Nangla Battu ranks lowest in social condition index. Large family size, high percentage of dropouts and larger proportion of working children in this slum are attributed towards low social conditions here. Most of the sampled households here do not send their children to school. The parents are not aware of the importance of education and even those who understand are tied because of the poor economic conditions. They believe in adding more members to their family. Children are considered assets to the households. According to them more working members in their family will contribute more in their total household income. Hence high population growth can be seen in these regions which lead to higher dependency ratio, larger family size and population working under 14 years of age. Nangla Battu presents slightly better social conditions than Shobhapur but it has lowest percentage of literate slum dwellers. Illiterate people are unaware of their rights, trapped into various social evils and couldn't get out of their pity and miserable conditions. It limits their opportunities to take part in the community at an equal platform. Hence it makes them vulnerable group in society. Slum dwellers of Phelera possess low social conditions mainly because of having large section of dropouts and consequently large percentage of child workers. Notified slums have comparatively high social condition indices. Social conditions are high in Chandra Shekhar Colony and Uttam Nagar. Jamna Nagar has medium status of social conditions due to large family size, low literacy rate and high prevalence of child labour. Uttam Nagar has high status of social conditions still it has highest percentage of dropouts among notified slums.

\subsection{Economic Conditions}

Table 3 revealed that all non-notified slums have low status of economic conditions. Nearly $83 \%$ people in Nangla Battu, 70\% people in Phelera and 69\% people in Shobhapur slums have irregular employment. This substantiates the fact that educational level and location of residence have influence on their employment type. Irregular employment causes insecurity and financial problems which may lead to various social evils and crimes. The bad consequences for individual employees extend out to bad effects on families and communities. Among notified slums, Chandra Shekhar Colony ranks first in economic conditions followed by Uttam Nagar and Jamna Nagar. Irregular employment and higher proportion of income spent on food items in Uttam Nagar and low monthly household income in Jamna Nagar resulted in comparatively lower economic conditions.

Low income characteristically means poor nutrition, poor housing, elementary or no education, little or no medical care. Slum dwellers non-notified slums of Nangla Battu and Shobhapur have low income. Slum dwellers of Notified slum of Jamna Nagar and non-notified slum of Phelera have medium income while slum dwellers of notified slums of Chandra Shekhar colony and Uttam Nagar have high income. The percentages of families spending more than 75 per cent of their income on food items are high in non-notified slums. Nangla Battu and Phelera have high proportion of income spent on food items. Shobhapur has medium status in terms of expenditure on food items while slum dwellers in all notified slums spend less proportion on food items (See Table 3). The findings reveal the poor economic conditions of the slum dwellers. Whatever they earn, it is spent on daily needs. The urban labour market affected slum dwellers in two ways, firstly, they faced discrimination due to irregular and unorganized nature of urban labour market and secondly they are harassed due to irregular wage provisions and low payment. Thus, urban labour market especially unorganized sector, has deteriorated their standard of life, consumption and expenditure patterns and put them into poverty.

Table 2. Social condition indicators, index and ranking of the sampled slums in Meerut city

\begin{tabular}{|c|c|c|c|c|c|c|c|c|c|c|}
\hline & \multicolumn{2}{|c|}{ Family size } & \multicolumn{2}{|c|}{ Literacy } & \multicolumn{2}{|c|}{ Drop outs } & \multicolumn{2}{|c|}{ Working children } & \multicolumn{2}{|l|}{ SCI } \\
\hline & Average & Index & $\%$ & Index & $\%$ & Index & $\%$ & Index & Index & Rank \\
\hline \multicolumn{11}{|l|}{ Notified slums } \\
\hline Jamna Nagar & 5 & 0.6 & 16 & 0.39 & 53 & 0.63 & 21 & 0.76 & 0.59 & 3 \\
\hline Chandra Shekhar Colony & 4 & 0.8 & 27 & 1 & 39 & 1 & 10 & 0.93 & 0.93 & 1 \\
\hline Uttam Nagar & 3 & 1.0 & 20 & 0.61 & 56 & 0.89 & 13 & 1 & 0.87 & 2 \\
\hline \multicolumn{11}{|l|}{ Non-notified slums } \\
\hline Phelera & 6 & 0.4 & 14 & 0.28 & 69 & 0.41 & 51 & 0.11 & 0.30 & 4 \\
\hline Nangla Battu & 8 & 0 & 12 & 0.17 & 80 & 0 & 56 & 0 & 0.04 & 6 \\
\hline Shobhapur & 7 & 0.2 & 9 & 0 & 66 & 0.52 & 41 & 0.33 & 0.26 & 5 \\
\hline
\end{tabular}


Table 3. Economic condition indicators, index and ranking of the sampled slums in Meerut city

\begin{tabular}{|c|c|c|c|c|c|c|c|c|}
\hline \multirow{2}{*}{ Slums } & \multicolumn{2}{|c|}{ Irregular employment } & \multicolumn{2}{|c|}{$\begin{array}{l}\text { Mean monthly household } \\
\text { income (INR) }\end{array}$} & \multicolumn{2}{|c|}{$\begin{array}{l}\text { Three fourth share of income } \\
\text { on food items }\end{array}$} & \multicolumn{2}{|l|}{ ECI } \\
\hline & $\%$ & Index & Mean & Index & $\%$ & Index & Index & Rank \\
\hline \multicolumn{9}{|l|}{ Notified slums } \\
\hline Jamna Nagar & 39 & 0.81 & 10000 & 0.60 & 41 & 0.85 & 0.75 & 3 \\
\hline Chandra Shekhar Colony & 29 & 1.00 & 12000 & 1.00 & 34 & 1.00 & 1.0 & 1 \\
\hline Uttam Nagar & 42 & 0.76 & 11500 & 0.90 & 45 & 0.77 & 0.81 & 2 \\
\hline \multicolumn{9}{|l|}{ Non-notified slums } \\
\hline Phelera & 70 & 0.24 & 9500 & 0.50 & 72 & 0.21 & 0.31 & 4 \\
\hline Nangla Battu & 83 & 0 & 8000 & 0.20 & 82 & 0.00 & 0.06 & 6 \\
\hline Shobhapur & 69 & 0.26 & 7000 & 0 & 60 & 0.46 & 0.24 & 5 \\
\hline
\end{tabular}

The exchange value of $1 \$$ in Indian Rupees at the time of survey was Rupees 60.

\subsection{Health Condition}

Remarkable variation was found in spatial health conditions in the sampled slums. All non-notified slums have low health conditions and all the notified slums have high health conditions (Table 4). Access to health care is essential for ensuring a community's general health status especially among low income groups. Utilization of health care facilities results in improvement of public health.
Health care utilization pattern in the sampled slums shows that nearly $35 \%$ of the households in Shobhapur, $27 \%$ of the households in Phelera and only $19 \%$ of the households in Nangla Battu are using government health facilities. All these non-notified slums have low status in utilizing health care facilities. Among notified slums Uttam Nagar has medium level of health care utilization where $56 \%$ of the households are using public health care facilities.

Table 4. Health condition indicators, index and ranking of the sampled slums in Meerut city

\begin{tabular}{|c|c|c|c|c|c|c|c|c|c|c|}
\hline \multirow[t]{2}{*}{ Slums } & \multicolumn{2}{|c|}{ Access to health care } & \multicolumn{2}{|c|}{$\begin{array}{l}\text { Women visited } \\
\text { hospitals for ANC }\end{array}$} & \multicolumn{2}{|c|}{$\begin{array}{l}\text { Children received } \\
\text { full immunization }\end{array}$} & \multicolumn{2}{|c|}{$\begin{array}{l}\text { People suffering from } \\
\text { infectious diseases }\end{array}$} & \multicolumn{2}{|l|}{ HCI } \\
\hline & $\%$ & Index & $\%$ & Index & $\%$ & Index & $\%$ & Index & Index & Rank \\
\hline \multicolumn{11}{|l|}{ Notified slums } \\
\hline Jamna Nagar & 76 & 0.90 & 9 & 0.58 & 13 & 0.47 & 42 & 0.81 & 0.69 & 3 \\
\hline Chandra Shekhar Colony & 82 & 1.00 & 14 & 1.00 & 22 & 1.00 & 36 & 1.00 & 1.0 & 1 \\
\hline Uttam Nagar & 56 & 0.59 & 11 & 0.75 & 17 & 0.71 & 38 & 0.94 & 0.74 & 2 \\
\hline \multicolumn{11}{|l|}{ Non-notified slums } \\
\hline Phelera & 27 & 0.13 & 6 & 0.33 & 11 & 0.35 & 59 & 0.28 & 0.27 & 4 \\
\hline Nangla Battu & 19 & 0 & 2 & 0 & 5 & 0 & 68 & 0 & 0 & 6 \\
\hline Shobhapur & 35 & 0.25 & 3 & 0.08 & 8 & 0.18 & 61 & 0.22 & 0.18 & 5 \\
\hline
\end{tabular}

Low status of antenatal care (ANC) was found in non-notified slums. Nearly $6 \%$ women in Phelera, 3\% women in Shobhapur and only 2\% women in Nangla Battu visited hospitals for pregnancy related health problems. Among notified slums Jamna Nagar has medium level of antenatal care where $9 \%$ women visited hospitals for check up. Chandra Shekhar Colony (14\%) and Uttam Nagar (11\%) have relatively higher status of antenatal care. Health seeking behavior is lower in most of the sampled households. Immunization of children was low in Nangla Battu and Shobhapur non-notified slums where only $5 \%$ and $8 \%$ children receive full immunization. Phelera non-notified slum and Jamna Nagar notified slum have medium status of immunization providing full immunization to $11 \%$ and $13 \%$ children respectively. Chandra Shekhar Colony and Uttam Nagar enjoy high level of immunization providing care to $22 \%$ and $17 \%$ children respectively.

Non-notified slums also have large number of people suffering from infectious diseases than notified slums. Poor water and unsanitary conditions led to adverse health outcomes in the households living in the slums in the study area. Field surveys revealed that the conditions of the houses of slum dwellers were very poor in terms of size, structure, multipurpose space where these people live, sleep and cook and share the company of animals. Their houses are characterized by dirt, filth with garbage pilfered everywhere. The surroundings were dirty, filthy and slushy. Conditions appeared to be worst in terms of access to certain basic amenities such as toilet facilities, sewerage facilities and garbage disposal. There is lack of drainage, toilet and drinking water facilities. Water logging of sullage around the houses was observed. Heaps of uncollected garbage were found lying open around the house. The unhygienic conditions attract vectors-mosquitoes, flies, cockroaches, rats, fleas, bugs, ticks, mites, etc. Bacteria thrive in the warm moist conditions. Rotting garbage spreads malaria, amoebiasis, dysentery, diarrhea, etc. Contaminated water contains viruses which cause jaundice, typhoid, etc. 
Stagnant sewage is a breeding ground for mosquitoes which causes malaria. A simple procedure of washing hands before eating and after toilets is not in habit. Due to these unhygienic environmental conditions, the slum dwellers are at a constant risk of health hazards and they suffer from a variety of diseases like malaria, typhoid, dysentery, skin problems, diarrhea, pneumonia, jaundice, etc.

\subsection{Composite Slum Conditions}

Slum condition index (Slum CI) was computed to rank slums with reference to its four components of household environmental condition index (HECI), social conditions (SCI), economic conditions (ECI) and health condition index (HCI) to assess the overall performance of slums (Table 5). Results indicate that non-notified slums have poor conditions as compared to notified slums. Among non-notified slums Nangla Battu has the lowest slum condition index. The slum dwellers of this slum have poor social condition, economic conditions and health care utilization. In Shobhapur and Phelera slum conditions are poor mainly because of poor household environmental conditions.

Table 5. Slum condition index and rank of the sampled slums

\begin{tabular}{lll}
\hline \multirow{2}{*}{ Slums } & \multicolumn{2}{l}{ Slum conditions } \\
& Index & Rank \\
\hline Notified slums & & \\
Jamna Nagar & 0.68 & 3 \\
Chandra Shekhar Colony & 0.95 & 1 \\
Uttam Nagar & 0.78 & 2 \\
Non-notified slums & & \\
Phelera & 0.28 & 4 \\
Nangla Battu & 0.10 & 6 \\
Shobhapur & 0.22 & 5 \\
\hline
\end{tabular}

Chandra Shekhar Colony among notified slums ranks first in slum condition index. It enjoys the first rank in all the four components of Slum CI. Uttam Nagar ranks second in slum condition index but it is poor in household environmental condition index while Jamna Nagar occupies third rank in slum condition. This slum has poor social, economic and health conditions. To access the relationship between Slum condition index and its four components, i.e., household environmental condition, social conditions, economic conditions and health conditions, Karl Pearson's two tailed correlation has been derived. The result shows that Slum condition index and its components are positively and significantly correlated (Table 6).

A bivariate regression was run between Slum CI and its causal factors to examine the most influencing component causing variation in Slum CI. When Slum CI was regressed upon the household environmental condition index, the social conditions, the economic conditions and health condition index came out to be positive and significant with R2 being $0.825,0.966,0.995$ and 0.992 respectively (See Table 6). A close perusal of Table 6 shows that in three variables viz. social conditions, economic conditions and health conditions the value of beta coefficient was significant at $99 \%$. The value of R2 was the highest in case of bivariate regression analysis between slum condition index and economic condition index. Therefore, it could be inferred that the economic conditions has a major impact on slum condition index among all the causal variables as $99.5 \%$ of variation in slum conditions was explained by variation in the level of economic conditions. The influence of household environmental conditions is least on slum conditions as the value of $\mathrm{R} 2$ is minimum and hence $82.5 \%$ variations in slum conditions was explained by variation of household environmental conditions. Thus it can be safely concluded that poverty is the main cause of poor slum conditions and social conditions, health conditions and household environmental conditions are the outcome factors of poor economic conditions in the sampled slums.

Table 6. Bivariate regression analysis between slum condition index and its four component indices

\begin{tabular}{|c|c|c|c|c|c|c|c|c|}
\hline \multirow{3}{*}{$\begin{array}{l}\text { Slum } \\
\text { condition } \\
\text { index }\end{array}$} & \multicolumn{2}{|c|}{ Household environmental conditions } & \multicolumn{2}{|c|}{ Social conditions } & \multicolumn{2}{|c|}{ Economic conditions } & \multicolumn{2}{|c|}{ Health conditions } \\
\hline & $\begin{array}{c}\text { Beta } \\
\text { Coefficient }\end{array}$ & $\mathbf{R}^{2}$ & $\begin{array}{c}\text { Beta } \\
\text { Coefficient }\end{array}$ & $\mathbf{R}^{2}$ & $\begin{array}{c}\text { Beta } \\
\text { Coefficient }\end{array}$ & $\mathbf{R}^{2}$ & $\begin{array}{c}\text { Beta } \\
\text { Coefficient }\end{array}$ & $\mathbf{R}^{2}$ \\
\hline & $0.908^{*}$ & 0.825 & $0.983^{* *}$ & 0.996 & $0.998^{*}$ & 0.995 & 0.996 & 0.992 \\
\hline
\end{tabular}

**Correlation is significant at the 0.01 level (2-tailed)

* Correlation is significant at the 0.05 level (2-tailed).

Dependent variable: Slum condition index.

\section{Policy Implications}

Slum Condition Index as a policy tool pointed out not only the areas requiring attention of policy makers but also the priority thematic indicators in which strategies could be made to attain living standards and health improvements. The index helped in identifying interregional priorities for the allocation of resources relevant to each region for urban sustainable development.
Table 7. Priority areas for improving living conditions and health status

\begin{tabular}{ccccc}
\hline Slums & HECI & SCI & ECI & HCI \\
\hline $\begin{array}{c}\text { Notified slums } \\
\text { Jamna Nagar }\end{array}$ & & $\sqrt{ }$ & $\sqrt{ }$ & $\sqrt{ }$ \\
$\begin{array}{c}\text { Chandra Shekhar Colony } \\
\text { Uttam Nagar }\end{array}$ & $\sqrt{ }$ & & & \\
Non-notified slums & & & & \\
$\quad \begin{array}{c}\text { Phelera } \\
\text { Nangla Battu } \\
\text { Shobhapur }\end{array}$ & $\sqrt{ }$ & $\sqrt{ }$ & $\sqrt{ }$ & $\sqrt{ }$ \\
\hline
\end{tabular}


The slum condition index ranking implied that notified slums: Chandra Shekhar Colony, Uttam Nagar and Jamna Nagar performed better in slum conditions. All these slums have slum condition index more than 0.5 and were identified as having better conditions for sustainable living standards and health development. Similarly, the slums with slum condition index lower than 0.5 were identified as depressed areas possessing poor living and health conditions. The findings revealed that Nangla Battu, Shobhapur and Phelera with less than 0.5 slum condition indexes are the priority slums that require attention for improvement in living and health status (See Table 7). Nangla Battu should be given priority for improving social, economic and health status. Population policy for population stabilization should be strictly enforced for the development of smart and healthy city. In spite of various programmes promulgated by the government to increase the literacy rate among the masses by providing mid day meals, free books and free education up to primary level the situation has remained the same. Low literacy rate is reflected in their economic status. Since most of the slum dwellers are uneducated they are engaged in low paid jobs. They are hard pressed and send their children to labour market to supplement their income denying their precious childhood. Therefore, provision of vocational training programme for semi-skilled and unskilled labour should be made to alleviate poverty from among them. The slum dwellers should be made aware regarding importance of education and efforts should be made to change the attitude of slum dwellers towards child labour. Economic conditions of the slum dwellers of this slum should be given priority. Employment guarantee programme should be extended and at least one person from the family should be given employment. There is urgent need to make slum dwellers aware of complete and timely immunization. Very low percentage of women in the sampled slums received complete three or more antenatal visits during pregnancy. Thus urgent interventions are required to generate awareness among pregnant women to avail essential antenatal care during pregnancy to avoid any kind of complications and to have safe delivery.

Household environmental conditions should be accorded higher priority over social conditions, economic conditions and health conditions in Shobhapur, Phelera and Uttam Nagar. Provision of basic facilities of safe drinking water and sanitation facilities should be made available by the city municipal board. Municipal cooperation of the city should also ensure proper management of solid wastes. India's Draft National Slum Policy calls for community driven imitative in the health sector. The community should be mobilized to create demand for better prevention, health services and to access these services in a more effective manner. Hygiene behavior changes should be promoted as an integral part of the sanitation services (Asha Seattle Team 2006). Slum dwellers' perception of improvement in slum conditions concur with the findings of worsening conditions in slums. A large majority reported of lack of improvement in the conditions of garbage disposal, latrines, electricity, sewage, approach roads, water supply and drainage. It is not unusual that in some slums where poverty and misery prevails T.V sets, refrigerators and radios are also blaring examples (Sud 2006). Slum dwellers have to rely heavily on political networks for improvement in living conditions. Politicians want to maximize support while expending minimal campaign funds. Some slum dwellers whose survival depends upon these leaders in the form of land recognition, amenities or public works programmes present politicians with easy pickings. Though government of India has implemented various programmes such as Rajiv Awas Yojana (Rajiv Housing Programme), Integrated Housing \& Slum Development Programme (IHSDP), Jawaharlal Nehru National Urban Renewal Mission (JnNURM) for improving infrastructure and quality of life in slums, the improvements have not occurred to the desired level. Lack of coordination among state departments and local urban bodies resulted in poor delivery of services. Recently Government of India has launched National Urban Health Mission (NUHM) and it is presumed that its effective implementation would perhaps make a difference in living standards and health conditions of rightly said "Less Fortunate Slum Dwellers".

\section{Conclusion}

The paper analyzed priority issues concerning living conditions and health status in notified and non-notified slums of a fast growing city. Slum condition index as a composite index of its four components of HECI, SCI, ECI and HCI has proved to be a powerful tool for identifying priorities required for the development of healthy and smart city. The results demonstrated that slums are the outcomes of pull of economic prosperity and better employment opportunities in the Meerut city together with push of social ostracism. Poverty created slums and slums breeded hopelessness. Socio-economic profile as revealed in the study is appallingly low. Slum condition index based analysis provided insights into relative status of slums and priorities to be given in each component. Slum condition index identified slums which require immediate attention for improvement in their respective socio-economic and health conditions. Non-notified slums were found to have poor slum conditions and thus call for timely policy interventions. Social condition, economic conditions and health condition should be accorded higher priority over household environmental conditions in Nangla Battu. In Shobhapur and Phelera household environmental conditions should be accorded higher priority over social, economic and health conditions. The study has also identified priorities for the slums which have better slum conditions. For instance, in Jamna Nagar, social, economic and health conditions and in Uttam Nagar household environmental conditions should be given higher priority. Thus slum condition index based approach can be utilized for assessing welfare programmes and their relative status in slums, and providing holistic framework for healthy city. 


\section{Acknowledgement}

The author gratefully thanks the anonymous reviewers for the valuable comments and suggestions to improve the quality of the manuscript.

\section{References}

[1] Asha Seattle Team.2006. Urban Slums in India: the myths and the reality. Asha Seattle Quarterly Newslett. 12 (2):1-2.

[2] Bolay JC. 2006. Slums and Urban Development: Questions on Society and Globalization. The European Journal of Development Research.18 (2):284-298.

[3] Census of India 2001. Primary Census Abstract. Office of the Registrar General and Census Commissioner. Ministry of Home Affairs, Government of India.

[4] Census of India 2011. Primary Census Abstract. Office of the Registrar General and Census Commissioner. Ministry of Home Affairs, Government of India.

[5] Chandrasekhar S. 2006. Growth of slums Availability of Infrastructure and Demographic outcomes in Slums: Evidence from India. Indira Gandhi Institute of Development Research, Mumbai. Paper presented at the 2005 Annual Meetings of the Population Association of America, Philadelphia.

[6] District Census Hand Book of Meerut. 1961. Directorate of Census Operation, Lucknow, Uttar Pradesh, India.

[7] District Census Hand Book of Meerut. 2011. Directorate of Census Operation, Lucknow, Uttar Pradesh, India.

[8] Dyson T. 2011. The role of the demographic transition in the process of urbanization. Population and Development Review. 37(1): 34-54.

[9] Edelman B, Mitra A. 2006. Slum Dwellers' Access to Basic Amenities: The Role of Political Contact, its Determinants and Adverse Effects. Review of Urban \& Regional Development Studies. 18(1):25-40.

[10] Goli S, Arokiasamy P, Chattopadhayay A. 2011. Living and health conditions of selected cities in India: Setting priorities for the National Urban Health Mission. Cities. 28:461-469.

[11] Harpham T, Burton S, Blue I. 2001. Healthy city projects in developing countries: the first evaluation. Health Promotion International. 16(2): 111-125.

[12] Hatai LD, Sen C. 2008. An Economic Analysis of Agricultural Sustainability in Orissa. Agricultural Economics research Review. 21: 273-282.

[13] Jawaharlal Nehru National Urban Renewal Mission 2006. Consultancy Services for preparation of the City Development Plan for Meerut in the state of Uttar Pradesh under JNNURM. Ministry of Urban Development, Government of India, New Delhi.

[14] Karn SK, Shikura S, Harada H. 2003. Living Environment and Health of Urban Poor: A Study in Mumbai. Economic and political Weekly. 23:3575-3586.

[15] Ministry of Housing and Urban Poverty Alleviation.2011. Report of the Committee on Slum Statistics/Census.
Government of India, New Delhi.

[16] National Sample Survey Organization. 2003. Condition of Urban Slums-2002: Salient Features. NSS 58th Round. Ministry of Statistics and Programme Implementation. Government of India. Report. 486:58/0.21/1.

[17] National Urban Health Mission. 2012. Framework for Implementation. Ministry of Health and Family Welfare. Government of India, New Delhi.

[18] Parkins NC. 2010. Push and Pull Factors of Migration. American Review of Political Economy 8:2:6-24.

[19] Parkinson J. 2007. Improving environmental health outcomes of slum upgrading projects. Report commissioned for the World Bank. Washington, DC: World Bank.

[20] Rasool F, Botha CJ, Bisschoff CA. 2012. Push and Pull Factors in Relation to skills shortages in South Africa .Soc Sci. 30 (1):11-20.

[21] Redman C, Nancy SJ. 2005. The environmental, social and health dimensions of urban expansion. Population and Environment. 26(6):505-520.

[22] Sajjad H, Singh AL, Kumar H. 2005. The Environmental Impact of Cities: A Case Study. The Geographer. 52(2): 14-27.

[23] Sajjad H, Nasreen I, Ansari, SA. 2014. Assessing Spatio-temporal Variation in Agricultural Sustainability Using Sustainable Livelihood Security Index: Empirical Illustration from Vaishali District of Bihar, India. Agroecology and Sustainable Food Systems. 38:46-68.

[24] Sajjad H, Singh AL, Kumar H. 2008. Socio-economic and Health Conditions of Slum Dwellers in Meerut city, Uttar Pradesh. National Geographical Journal of India. 54 (3-4):103-116.

[25] Saleth RM, Swaminathan MS. 1993. Sustainable Livelihood Security at the Household Level: Concept and Evaluation Methodology. In: Proceedings of an Interdisciplinary Dialogue on Ecotechnology and Rural Employment. Madras, India.

[26] Sharma K. 2006. Cityscapes: The future is urban. The Hindu Survey of Environment.7-11.

[27] Singh PK, Hiremath, BN. 2010. Sustainable Livelihood Security Index in a Developing Country: A Tool for Development Planning. Ecological Indicators. 10: 442-451.

[28] Sud H. 2006. Poverty and Slums in India: Impact of Changing Economic Landscape. South Asian Analysis Group. Paper No. 1769. http://www.saag.org.

[29] Swaminathan MS. 1991. From Stockholm to Rio De Janeiro: the Road to Sustainable Agriculture. In: Monograph 4: MS Swaminathan Research Foundation, Madras, India.

[30] United Nations Development Programme. 1990. Human development report. New York: Oxford University Press.

[31] United Nations Development Programme. 1992. Human development report. New York: Oxford University Press.

[32] World Health Organization.1995. Building a healthy city: A practitioner's guide. WHO, Geneva. 